\title{
Study on How to Cultivate the Innovational Thought of Students Majoring in Art Design
}

\author{
Chengyuan Ren ${ }^{1,}$, Jinling $\mathrm{Du}^{2, b}$ \\ ${ }^{1}$ cheng-yuan REN,Tianjin Polytechnic University, Tianjin ,China \\ 2jin-ling DU,Tianjin Polytechnic University, Tianjin ,China \\ arenchengyuan@hotmail.com, b15102224892@163.com
}

\begin{abstract}
Keywords: Art design; Innovative thought; Teaching and Research
Abstract.Innovation is increasingly becoming essential indicator for measuring talents, the cultivation of innovation ability is especially important for the students majoring in art design while learning book knowledge. On the one hand, innovation is not only the call of the times, but also the requirements of the new curriculum reform; on the other hand, the university art education has incomparable advantages in cultivating students' innovative ability. This paper introduces the idea of cultivating innovate thinking and ability in many respects, such as inspiring students use innovative thinking positively, guiding students to participate in all levels of innovation competitions, carrying out diversified artistic innovations in social practice activities, and cultivating talents in enterprises. It is extremely valuable for universities to teach and practice innovation and for students to develop innovation ability.
\end{abstract}

\section{Introduction}

Innovative thought is the new requirement for contemporary students majoring art design. At present, the teaching mode in China's art design is a continuation of the traditional teaching oriented model. This form is not able to improve students' interest in learning or adapt to the demand of social development. In this way, students cannot combine knowledge with practice. The cultivation of students' innovation consciousness who major in art design in universities has called the attention of decision maker. Thus, the research and implementation method on enhancing the scientific theory of innovative consciousness of the students majoring in art design is of great significance to cultivate high-quality, capable and full of art design innovation consciousness talents. To improve the capability of independent innovation of students majoring in art design, the art design teaching styles and methods need to be reformed. Only in this way, can we cultivate the art-designing talents with innovative thought and connect with society more adequately.

\section{More proportion of elective courses to train students' ability of comprehensive knowledge}

Due to various reasons, curriculum in the traditional art school has considerable limitations in measure and target which mostly base on teaching mode converse from traditional arts and crafts and plastic arts. These courses put a high value on general skill-training and ignore the role of the theoretical basis and humanistic knowledge in cultivating skills, and they are isolated from each other between each course lacking organic links.

We should break the discipline inherent in concepts. Essentially speaking, there are no clear boundaries between the various artistic disciplines. We should increase the proportion of elective courses in the curriculum, and starting with the interest of the students to inspire the students' innovative thought, strengthen students' artistic accomplishment, and cultivate students' comprehensive ability so that they can develop into comprehensive art talents. To enhance the creativity and openness of curriculum system, it is necessary to improve the proportion of professional elective credits and the number of professional elective classes instead of neat uniform curriculum programs, so that students can follow their own interests and needs to study to some extent. Different sectors of the society should do their best to expand the field of public optional 
courses in the field of knowledge, encourage students to cross the professional elective courses, promote the interdisciplinary penetration of the subject and improve the student's intelligent structure. For example, the college offer 21 courses including wrought copper, sculpture, lacquer ware, pottery, printing, fiber, photography and other experimental teaching curriculum to meet the needs of innovative practice teaching, so that they can lead students to create individually and innovatively in extra-curricular meet individual students 'extracurricular innovation and creativity, cultivate students' ability to use comprehensive knowledge innovatively.

\section{More international exchange and cooperation to expand students' horizons andlearn innovative perspectives and methods}

What we should do is to build a bridge of cooperation with foreign innovative art and design institutions actively and improve teachers' overall internationalized vision. The art design of some advanced countries in Europe and America has entered a relatively mature stage of development. Through cooperation with these institutions, we can learn from them and adopt some the innovative teaching mode and concept. Chinese and foreign teaching environment, the equipment of interaction, sharing of resources, interactive communication between teachers and students, to improve the quality of teaching, training students innovative thinking and ability, opened a door leading to the internationalization.

\section{More attention to the training depth and study through to the professional knowledge, curriculum into ladder system}

Currently, our art and design education is mainly stay in the surface layer of books education. We must strengthen the depth of culture, emphasize on students' understanding of professional knowledge and absorption and stimulate the students' study assiduously. In this way, students can easily accept courses from the deep to shallow and develop innovative thinking mode.

After completing the basic teaching in class, teachers layout related assignments and topics, and students form different groups to discuss the final report and summary programs which strengthen the process of students' ability to grasp knowledge and understand it. It essentially means the art of innovative teaching practice could divided into three phases, the first stage is to undergo, comprehend and understand the practice; the second stage is to create the formula, achieve, and personalized practical aspects; the third stage is to do adaptive, professional and practical type of social practice teaching. The relationship between these three stages are progressive layers. The first stage is to understand and grasp the book knowledge including basic theory and the concept of principles, and in this stage it is completed by students' self-practice. The second stage is to transform the students' creativity and design scheme into reality through practice. The third stage is to cultivate the students' professional skills through the connection of students and society to connect with society. From the grasp of abstract theories and concepts, to self-innovation thought experience, and the acquisition of innovation ability ultimately, these three stages combine over dimension to stimulate the creative enthusiasm of students, develop the creative thinking of the students, and stimulate students' enthusiasm for innovation.

\section{The application of heuristic teaching method should be individualized instead of being stereotyped}

At present, many art design education still use the traditional teaching methods. Traditional teaching is teaching oriented model which gives priority to teachers' teaching instead of paying attention to collect student feedback information or the main role of the students. Teachers should pay attention to the cultivation of students' creativity and individuality, and try their best to emphasize the teaching idea of "people oriented". We foster students majoring in art design emphasizing on the aesthetic ability, professional skills and innovative design of the three aspects of the common improvement, 
should respect the law of the art of professional education, emphasis on innovative teaching. The innovative teaching content contains two aspects: one is the teaching content of innovative options. Such as on each phase of the project Settings, there must be some flexibility, for different development direction into a number of sub projects, and give students plenty of option. Second, the teaching process of innovative training. Such as on the combination of the project team, teachers should macro-control and individualized according to each student's characteristics and strengths, let the students play different roles in the group, have different innovative training. For example a good artistic skills and more thorough understanding of the design students focus on the cultivation of the creative design aspects; Understand the thinking strong students can strengthen their learning and mastering of the software, in order to fulfill expertise in computer cartography effect; for hands-on ability students can make in terms of the model, strengthening the training of furnitures. For different students, to carry out innovative inspiration, to cultivate innovative talents.

\section{Actively participate in international and domestic competitions, to communicate, and facilitate students to develop innovative ideas}

To change the traditional closed type teaching system, increase the proportion of actual design project courses in teaching, and actively organize students to participate in the design practice, design competitions, such as project design, combine the student's ability to design and the actual need of the market. Our school often organize students to participate in large domestic and international competitions, through the game again and again, students clear their own position, to make up for their weaknesses, and understanding throughout the students ' creativity, to communicate and Exchange, improve our work and innovative ideas, conducive to the development of students' innovative thinking in the design. Students learn through competition with domestic and international universities, and understand other people's point of view innovative methods, within the frontier border comparison is how the design, how he is thinking, which, we get the recognition and promotion of innovative thinking, the ability to get exercise.

\section{Pay attention to practice teaching, meticulous, a large number of experiments}

Whether the education of art design majors can achieve the characteristics of running a school is decided by the innovation of practical teaching. However,as a result of college education, educational philosophy and money into a series of problems, lack of practice base, art and design professional teaching practice and the market docking mechanism is not perfect, unreasonable curriculum, teaching mode, which led to teaching practice is easy to ignore in cross and comprehensive design disciplines, making the College of Art and design education in improving the creativity of students do not come out to play. In order to solve this problem, when teaching should strengthen the students' innovative thinking training course, the design elements of the association, organization, refining and other logic thinking and ability training, to carry out a large number of innovative teaching, and explore innovative teaching road with contemporary art and design. Through a large number of meticulous innovative teaching practice, students' creative thinking and creative techniques to be most vividly demonstrated. Nowadays, innovation and entrepreneurship is the theme, to encourage students to actively innovation, find a breakthrough point of the design, to meet the market demand, Internet, artificial intelligence, a new green energy, these areas are at present market demand and forward-looking strong link, students can around these perspectives, strengths, design innovation and entrepreneurship. For example: using eco-friendly materials to replace traditional materials design lamps, such as interactive pattern applied to traditional commodities, another example of solar power tools and so on, as long as hard work and practice, thoughtful and meticulous, in a large number of experiments can pays off. 


\section{Production-study-research cooperation, students with market practice}

University-enterprise cooperation, the establishment of mutually beneficial and win-win cooperation relationship between schools and enterprises. On one hand, schools can put enterprises advanced equipment, the project introduced to the practice of classroom teaching in order to improve teachers, students' practical ability and operation ability, at the same time to provide paid services for enterprises; On the other hand, through the cooperation with enterprises, school teachers and the enterprise can create a two-way communication between senior designer, to make up for teaching relatively closed environment, and the situation of society, improve the teachers and the students' practical ability to innovate. Meanwhile, in the design of teaching increase the number of research topics consciously, so that students will be able to design their own creative and practical design projects combine to create. The cultivation of independent innovation ability requires students to change passive learning into active research, students and teachers, students and students to achieve two-way interaction, using different methods to solve the problem of creative.

\section{Summary}

Innovation is the soul of a nation's progress and an inexhaustible motive force for the prosperity of a country. Innovation ability is the soul of the progress and development; innovation ability is the source of sustainable development; innovative ability is the main way to improve the comprehensive strength and economic benefits. Being active and creative ability of students, educators should actively guide the student to put their own innovation talents, constantly enrich himself, will be of theoretical knowledge learned in the textbooks of good use to the innovation practice. Students' innovative thinking and ability training is the important way to realize the efficient integration of production, study and research of the development, is an effective countermeasure to alleviate employment pressure, it is necessary part of culture innovative nation-building needs of the high-level innovative talents. In the design of professional education, teachers and students should work together to explore and practice the students' innovation and entrepreneurship training, make creative design dreams come true.

\section{References}

[1] Liu Ying, Ai Hong. Innovative design ideas and techniques [M].Beijing: Mechanical Industry Press, 2004

[2] Zhou Yanbo, Guo Xingquan. Innovative design thinking and ability [M].Beijing: Science Press, 2004

[3] Mao Baitao, To develop the innovative ability of art design teaching mode [J].Journal of laboratory research and exploration, 2008, 27(4):5-6.

[4] Quan Litao, Innovative practice of teaching mode of art design and practice skill studio [J].decoration. 2010(10):133-134.

[5] Alena, Thoughts on the Artistic Design Education. Art panorama .2006.11 